\title{
The UV and IR Comparative Spectrophoto- metric Study of Some Saturated and Lacunary Polyoxometalates
}

\author{
Grama Lavinia¹, Boda F¹, Gaz Florea AS², Curticăpean A, Muntean Daniela-Lucia³ \\ 1 Department of General and Inorganic Chemistry, Faculty of Pharmacy, University of Medicine and Pharmacy, Tîrgu Mureș, Romania \\ 2 Department of Organic Chemistry, Faculty of Pharmacy, University of Medicine and Pharmacy, Tîrgu Mureș, Romania \\ 3 Department of Analytical Chemistry and Drugs Analysis, Faculty of Pharmacy, University of Medicine and Pharmacy, Tîrgu Mureș, Romania
}

\begin{abstract}
Objectives: The polyoxometalates are a class of inorganic compounds with controllable shapes and sizes, and with excellent properties that make them attractive for various applications. This study is aimed at the comparative UV and IR spectra of Keggin type polyoxometalates.

Methods: Compounds under (UV and IR) investigations were divided into several groups to highlight similarities between compounds or classes of compounds for the same category. There are four types of saturated Keggin structures and six lacunar compounds included in this study. The study begins with the UV investigations on aqueous solutions with $10^{-5} \mathrm{M}$ concentration for these compounds. IR spectra were recorded as $\mathrm{KBr}$ pressed pellets.

Results: The UV spectras presents large strong peaks between 185-195 nm corresponding to W = Od bonds, between 251-268 nm for W-O-W bridge bonds, depending on heteroatom types (As, Sb). The unsaturated cryptand ligand having $\mathrm{Co}^{2+}$ coordinated presents the most intense peak, due to the involvement of oxygen atoms from terminal $W=$ Od coordinative bonds with high electronic densities in coordination of W-O-Co bond. The IR spectra present many peaks that are associated as follows: for terminal bonds $\mathrm{W}=\mathrm{Od}$, 955-970 $\mathrm{cm}^{-1}$; for $\mathrm{W}-\mathrm{O}$ W bridging bonds, $790-910 \mathrm{~cm}^{-1}$; for W-O-As/Sb bonds to heteroatom, $690-760 \mathrm{~cm}^{-1}$. Vibrations of the bonds between heteroatoms and oxygen (As/Sb-O) appear around 620-660 $\mathrm{cm}^{-1}$.
\end{abstract}

Conclusions: Similarities appear from the recorded spectra, between compounds of the same class, by category association. Very fine displacements of peaks that occur explain the influence of heteroatoms, addenda atoms or coordinated cations.

Keywords: polyoxometalates, spectroscopy, bonds association

Received: 11 June 2013 / Accepted: 21 October 2013

\section{Introduction}

The polyoxometalates, as transitional metal-oxygen clusters, are a class of inorganic compounds with controllable shapes and sizes, and with excellent properties that make them attractive for various applications [1,2]. This study follows the comparative UV and IR spectra of Keggin type polyoxometalates. Electronic loads of Keggin type anion are a very important factor influencing the structure of polyoxometalates [3].

The saturated or lacunar Keggin structures contain one tetrahedral coordinated heteroatom $\mathrm{XO}_{4}$ surrounded by twelve octahedral $\mathrm{MO}_{6}$ arranged in four groups of three octahedra linked by common edges and vertices of the tetrahedron central $\left(\mathrm{XM}_{12}\right)(\mathrm{X}=$ heteroatom, $\mathrm{M}=$ addenda $)$. Oxygen atoms delimit the structure [4]. The $\mathrm{MO}_{6}$ octahedra take shape because of the hexacoordination of addenda atoms (W, Mo in this case). Assemblies are due to the possibilities of condensation of these elements around the coordination of the polyhedra of heteroatoms (As, Sb in this case) $[5,6]$.

These structures present five isomers $\alpha, \beta, \gamma, \delta$, and $\varepsilon$ obtained by turning each $60^{\circ}$ of one, two or three triples

Correspondence to: Lavinia Grama

E-mail: grama.lavinia@yahoo.com against $\alpha$-isomer. As a result of chemical reaction, usually alkaline degradation, octahedral removal of one or more of the basic structure of polyoxometalates occurs to give unsaturated mono- or multi-lacunary with special properties $\left(\mathrm{XM}_{11}, \mathrm{XM}_{10}, \mathrm{XM}_{9}\right)[5,6]$.

Sidgwick describes four types of addendum-oxygen connections in polyoxometalate molecules [7] that are responsible for the appearance of peaks:

$-\mathrm{O}_{\mathrm{a}}$ - oxygen atoms connecting bridge between the heteroatom X and Addendum M (common both octahedron coordination of the Addendum and heteroatom $\mathrm{X}$ polyhedron);

$-\mathrm{O}_{\mathrm{b}}$ - oxygen atoms connecting bridge between two metal addenda atoms $\mathrm{M}$ located in two different sets of triplets $\mathrm{M}_{3} \mathrm{O}_{13}$;

$-\mathrm{O}_{\mathrm{c}}$ - oxygen atoms connecting bridge between two addenda atoms in the same group $\mathrm{M}_{3} \mathrm{O}_{13}$;

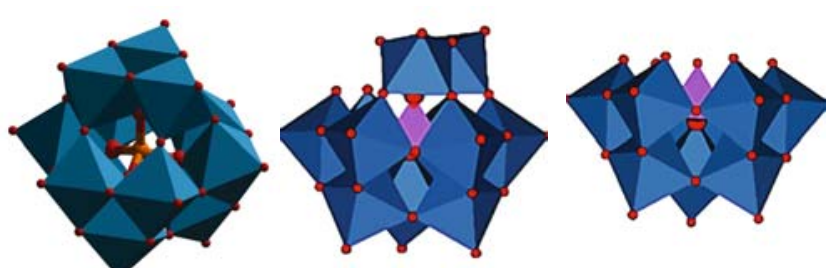

Fig. 1. Keggin structures 


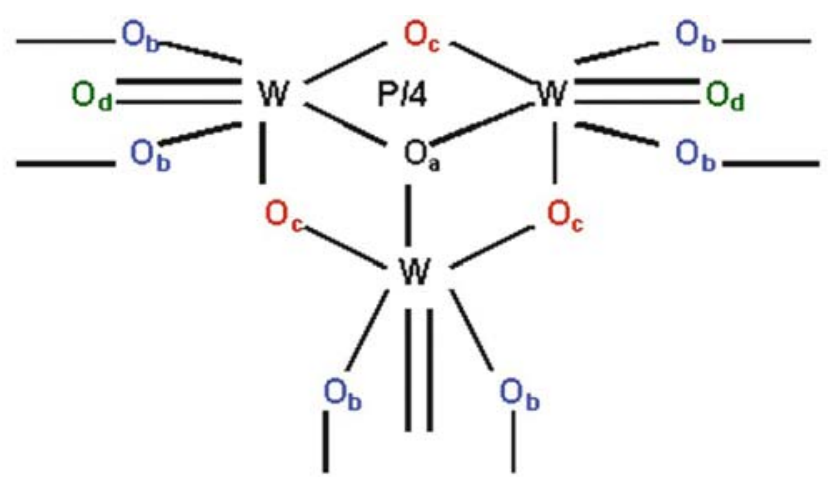

Fig. 2. Types of addendum-oxygen connections in polyoxometalates by Sidgwick [7]

$-\mathrm{O}_{\mathrm{d}}$ - terminal oxygen atoms belonging to the $\mathrm{MO}_{6}$ octahedron.

\section{Materials and methods}

Compounds under (UV and IR) investigations were divided into several groups to highlight similarities between compounds or classes of compounds for the same category. Some of the compounds were commercially purchased and used without further purification. Others were prepared according to the published methods $[8,9,10,11]$.

The studied compounds are:

a) Saturated compounds:

$$
\begin{aligned}
& -\mathrm{H}_{3}\left[\mathrm{P}\left(\mathrm{Mo}_{12} \mathrm{O}_{40}\right)\right] \mathrm{xH}_{2} \mathrm{O} \\
& -\mathrm{H}_{3}\left[\mathrm{P}\left(\mathrm{W}_{12} \mathrm{O}_{40}\right)\right]{ }^{*} \mathrm{xH}_{2} \mathrm{O} \\
& -\mathrm{H}_{4}\left[\mathrm{Si}_{12}\left(\mathrm{~W}_{12} \mathrm{O}_{40}\right)\right]{ }^{*} \mathrm{xH}_{2} \mathrm{O} \\
& -\mathrm{Na}_{3}\left[\mathrm{P}\left(\mathrm{W}_{12} \mathrm{O}_{40}\right)\right]{ }^{*} \mathrm{xH}_{2} \mathrm{O}
\end{aligned}
$$

b) Lacunary compounds:

$-\mathrm{K}_{7}\left[\mathrm{AsW}_{11} \mathrm{O}_{39}\right]^{*} \mathrm{xH}_{2} \mathrm{O}$

$-\mathrm{Na}_{8}\left[\mathrm{HAsW}_{9} \mathrm{O}_{33}\right] * \mathrm{xH}_{2} \mathrm{O}$

$-\mathrm{Na}_{8}\left[\mathrm{HSbW}_{9} \mathrm{O}_{33}\right] * \mathrm{xH}_{2} \mathrm{O}$

$-\mathrm{K}_{27}\left[\mathrm{KAs}_{4} \mathrm{~W}_{40} \mathrm{O}_{140}\right]^{*} \mathrm{xH}_{2} \mathrm{O}$

$-\mathrm{Na}_{27}\left[\mathrm{NaAs}_{4} \mathrm{~W}_{40} \mathrm{O}_{140}\right]^{*} \mathrm{xH}_{2} \mathrm{O}$

$-\mathrm{K}_{23}\left[\mathrm{KAs}_{4} \mathrm{~W}_{40} \mathrm{O}_{140} \mathrm{Co}^{(2+)}\right] * 40 \mathrm{H}_{2} \mathrm{O}$

UV measurements were made using a UV-VIS spectrophotometer AnalytikJena SPECORD 210 at $\lambda=190-400$ $\mathrm{nm}$ in $1 \mathrm{~cm}$ quartz cuvettes. The aliquots for the aqueous solutions had concentration of $10^{-5} \mathrm{M}$.

IR determinations were performed using Thermo Nicolet380 FTIR spectrophotometer and $\mathrm{KBr}$ pressed pellets, using a hydraulic press, were made for each compound.

\section{Results}

\section{a) UV determinations}

The study begins with the UV investigations on saturated compounds marketed: $\mathrm{H}_{3}\left[\mathrm{P}\left(\mathrm{Mo}_{12} \mathrm{O}_{40}\right)\right]{ }^{*} \mathrm{xH}_{2} \mathrm{O} /$ $\mathrm{H}_{3}\left[\mathrm{P}\left(\mathrm{W}_{12} \mathrm{O}_{40}\right)\right] * \mathrm{xH}_{2} \mathrm{O}, \mathrm{H}_{3}\left[\mathrm{P}\left(\mathrm{W}_{12} \mathrm{O}_{40}\right)\right] * \mathrm{xH}_{2} \mathrm{O} /$ $\mathrm{H}_{4}\left[\mathrm{Si}\left(\mathrm{W}_{12} \mathrm{O}_{40}\right)\right]{ }^{*} \mathrm{xH}_{2} \mathrm{O}, \mathrm{H}_{3}\left[\mathrm{P}\left(\mathrm{W}_{12} \mathrm{O}_{40}\right)\right]{ }^{*} \mathrm{xH}_{2} \mathrm{O} /$ $\mathrm{Na}_{3}\left[\mathrm{P}\left(\mathrm{W}_{12} \mathrm{O}_{40}\right)\right] * \mathrm{xH}_{2} \mathrm{O}$ Figure 3 .

Then, the determinations were made for:

- Themonolacunarycompounds: $\mathrm{K}_{7}\left[\mathrm{AsW}_{11} \mathrm{O}_{39}\right]{ }^{*} \mathrm{xH}_{2} \mathrm{O}$ - structure $\alpha$ / $\beta$ Figure 4.

- The trilacunary compounds: $\mathrm{Na}_{8}\left[\mathrm{HAs}_{9} \mathrm{O}_{33}\right]{ }^{*} \mathrm{xH}_{2} \mathrm{O} /$ $\mathrm{Na}_{8}\left[\mathrm{HSbW}_{9} \mathrm{O}_{33}\right]^{*} \mathrm{xH}_{2} \mathrm{O}$ Figure 5 .

For the clusters $\mathrm{K}_{27}\left[\mathrm{KAs}_{4} \mathrm{~W}_{40} \mathrm{O}_{140}\right] * \mathrm{xH}_{2} \mathrm{O} /$ $\mathrm{Na}_{27}\left[\mathrm{NaAs}_{4} \mathrm{~W}_{40} \mathrm{O}_{140}\right]^{*} \mathrm{xH}_{2} \mathrm{O}, \mathrm{K}_{27}\left[\mathrm{KAs}_{4} \mathrm{~W}_{40} \mathrm{O}_{140}\right]^{*} \mathrm{xH}_{2} \mathrm{O} /$ $\mathrm{K}_{23}\left[\mathrm{KAs}_{4} \mathrm{~W}_{40} \mathrm{O}_{140} \mathrm{Co}^{(2+)}\right] * 40 \mathrm{H}_{2} \mathrm{O}$ the $\mathrm{UV}$ spectres are shown in Figure 6.

\section{b) IR investigations}

The IR investigations were made on the same compounds and they are presented in the same order.

In Figure 7 are presented the IR spectra of the saturated compounds: $\mathrm{H}_{3}\left[\mathrm{P}\left(\mathrm{Mo}_{12} \mathrm{O}_{40}\right)\right] \mathrm{xH}_{2} \mathrm{O} /$ $\mathrm{H}_{3}\left[\mathrm{P}\left(\mathrm{W}_{12} \mathrm{O}_{40}\right)\right] * \mathrm{xH}_{2} \mathrm{O}, \mathrm{H}_{3}\left[\mathrm{P}\left(\mathrm{W}_{12} \mathrm{O}_{40}\right)\right]{ }^{*} \mathrm{xH}_{2} \mathrm{O} /$ $\mathrm{H}_{4}\left[\mathrm{Si}\left(\mathrm{W}_{12} \mathrm{O}_{40}\right)\right]{ }^{*} \mathrm{xH}_{2} \mathrm{O}, \mathrm{H}_{3}\left[\mathrm{P}\left(\mathrm{W}_{12} \mathrm{O}_{40}\right)\right] \mathrm{xH}_{2} \mathrm{O} /$ $\mathrm{Na}_{3}\left[\mathrm{P}\left(\mathrm{W}_{12} \mathrm{O}_{40}\right)\right]{ }^{*} \mathrm{xH}_{2} \mathrm{O}$.

In Figure 8 is presented the spectra of monolacunary $\mathrm{K}_{7}\left[\mathrm{AsW}_{11} \mathrm{O}_{39}\right]{ }^{*} \mathrm{xH}_{2} \mathrm{O}$ (structure $\alpha / \beta$ ) compounds.

After that, determinations were made for:

- Trilacunary compounds $\mathrm{Na}_{8}\left[\mathrm{HAs}_{9} \mathrm{O}_{33}\right]{ }^{*} \mathrm{xH}_{2} \mathrm{O} /$ $\mathrm{Na}_{8}\left[\mathrm{HSbW}_{9} \mathrm{O}_{33}\right]^{*} \mathrm{xH}_{2} \mathrm{O}$ in Figure 9

- Clusters in Figure 10, $\mathrm{K}_{27}\left[\mathrm{KAs}_{4} \mathrm{~W}_{40} \mathrm{O}_{140}\right]{ }^{*} \mathrm{xH}_{2} \mathrm{O} /$ $\left.\mathrm{Na}_{27}\left[\mathrm{NaAs}_{4} \mathrm{~W}_{40} \mathrm{O}_{140}\right]\right]_{\mathrm{xH}} \mathrm{H}_{2} \mathrm{O}$,

$\mathrm{K}_{27}\left[\mathrm{KAs}_{4} \mathrm{~W}_{40} \mathrm{O}_{140}\right] * \mathrm{xH}_{2} \mathrm{O} /$

$$
\mathrm{K}_{23}\left[\mathrm{KAs}_{4} \mathrm{~W}_{40} \mathrm{O}_{140} \mathrm{Co}^{(2+)}\right] * 40 \mathrm{H}_{2} \mathrm{O} \text {. }
$$

\section{Discussions}

Polyoxometalate class sizes characteristic vibration absorption for $\mathrm{M}-\mathrm{O}$ bonds appear in the specific frequency range of $190-400 \mathrm{~nm}$ for UV radiation and $400-2000 \mathrm{~cm}^{-1}$ for IR [12-18].

\section{a) UV determinations}

UV spectra show bands associated with terminal $\mathrm{W}=\mathrm{Od}$
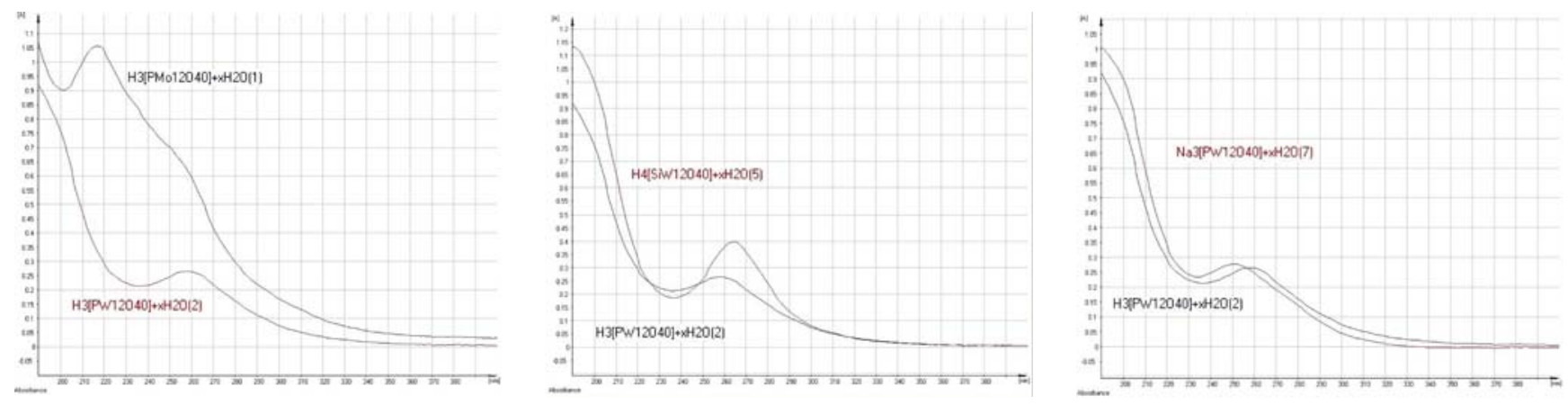

Fig. 3. UV spectra of the saturated compounds 


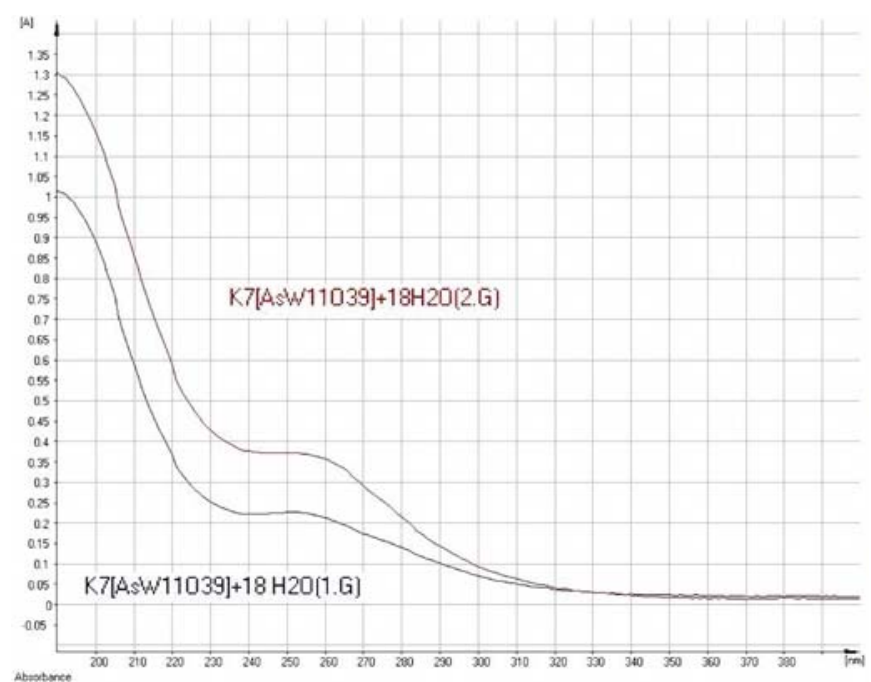

Fig. 4. Mono-lacunary $\mathrm{K}_{7}\left[\mathrm{AsW}_{11} \mathrm{O}_{39}\right]^{*} \mathrm{xH}_{2} \mathrm{O}$ (structure $\left.\alpha / \beta\right) \mathrm{UV}$ spectra

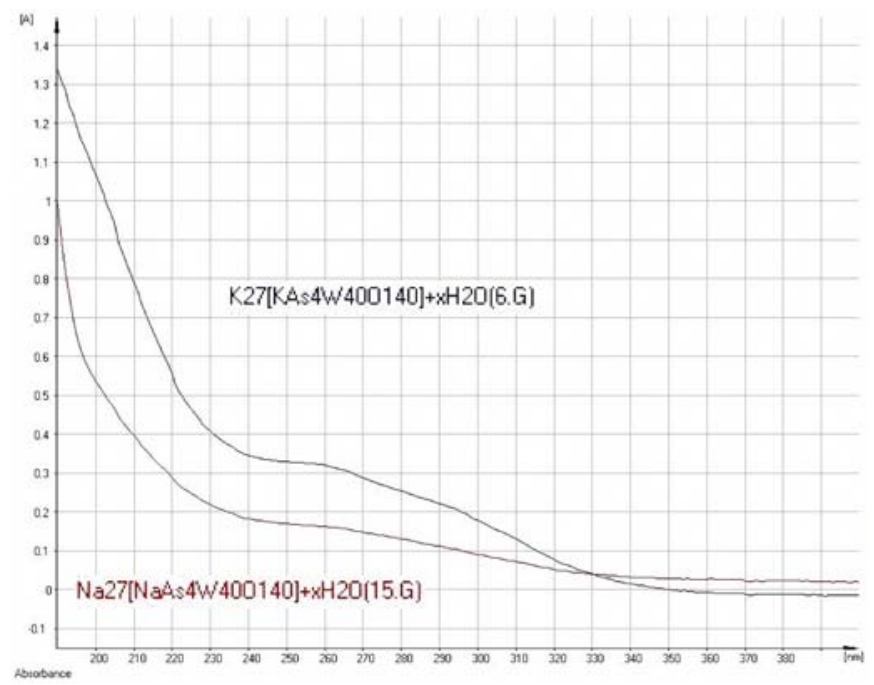

Fig. 6. UV spectra for clusters

links for $\pi \mathrm{p}-\mathrm{d}$ electronic transitions, and W-O-W characteristic tricentric links with oxygen atom bridged between two addenda atoms. Values in the spectra correspond to those found in the literature [12-14].

According to literature data, in order to link $\mathrm{W}=\mathrm{Od}$ a peak occurs at 185-195 nm. UV determinations were made in the range 190-400 $\mathrm{nm}$. Only the peak tail corresponding to $\mathrm{W}=\mathrm{Od}$ appears in the spectrum, but we noticed that the peak was very intense, which corresponds to higher binding energies.
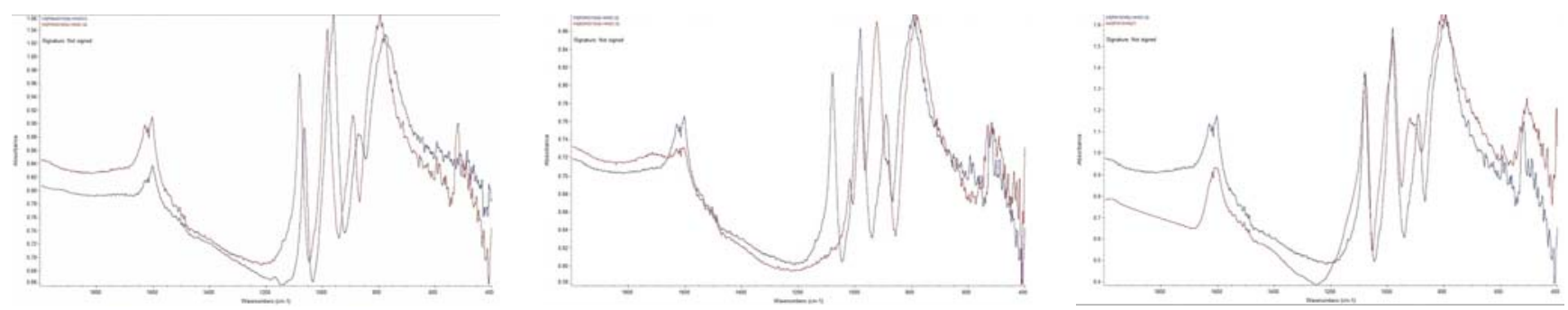

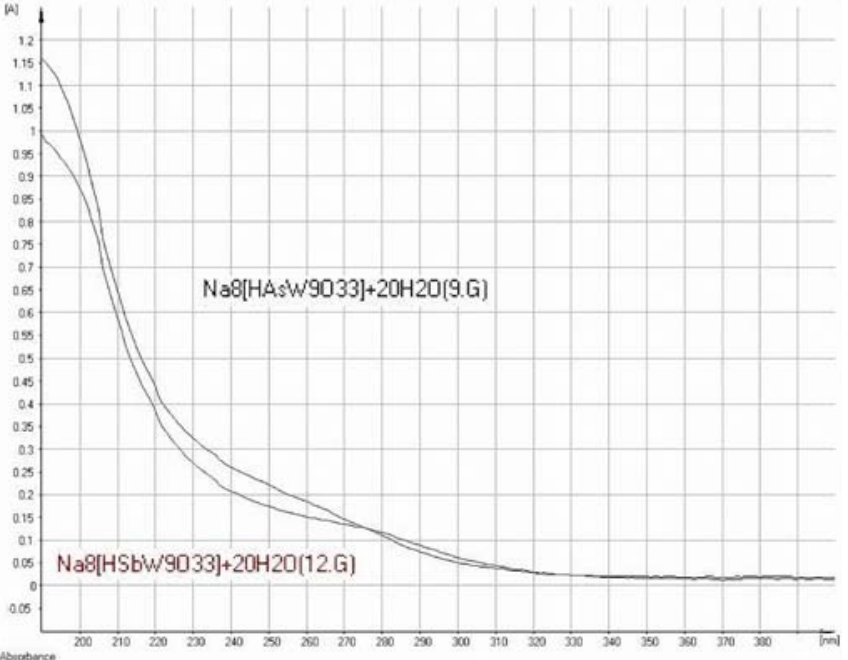

Fig. 5. UV spectra for trilacunary compounds

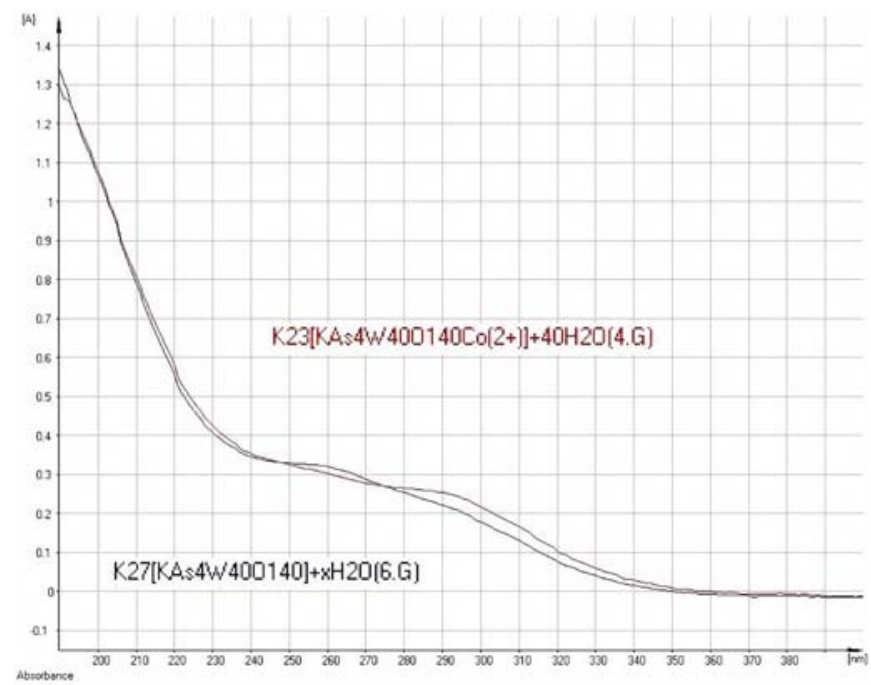

The UV spectra of saturated compounds $\mathrm{H}_{3}\left[\mathrm{P}\left(\mathrm{Mo}_{12} \mathrm{O}_{40}\right)\right] * \mathrm{xH}_{2} \mathrm{O} / \mathrm{H}_{3}\left[\mathrm{P}\left(\mathrm{W}_{12} \mathrm{O}_{40}\right)\right] * \mathrm{xH}_{2} \mathrm{O}$, $\mathrm{H}_{3}\left[\mathrm{P}\left(\mathrm{W}_{12} \mathrm{O}_{40}\right)\right] * \times \mathrm{H}_{2} \mathrm{O} / \mathrm{H}_{4}\left[\mathrm{Si}\left(\mathrm{W}_{12} \mathrm{O}_{40}\right)\right] * \mathrm{H}_{2} \mathrm{O}$, $\mathrm{H}_{3}\left[\mathrm{P}\left(\mathrm{W}_{12} \mathrm{O}_{40}\right)\right] * \mathrm{xH}_{2} \mathrm{O} / \mathrm{Na}_{3}\left[\mathrm{P}\left(\mathrm{W}_{12} \mathrm{O}_{40}\right)\right]^{*} \mathrm{xH}_{2} \mathrm{O}$ (Figure 3) present a second peak that is characteristic for W-OW bounds. Values are between $255-265 \mathrm{~nm}$. The most intense peak occurs for silicotungstic acid and is weakest for phosphomolybdic acid, which demonstrates the influence that both the heteroatoms and the addendum have on the structure. For sodium phosphotungstate the peak shifts

Fig. 7. IR spectra for saturated compounds 


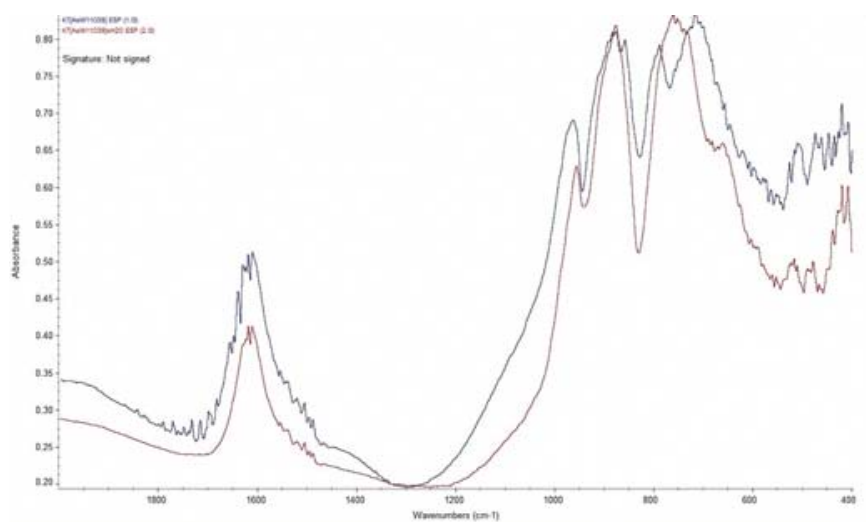

Fig. 8. IR spectra for monolacunary compounds

towards lower values of the wavelength so the structure is stabilizing.

The molar extinction for these compounds are: for $\left.\mathrm{H}_{3}\left[\mathrm{P}_{\left(\mathrm{W}_{12} \mathrm{O}_{40}\right)}\right)\right]^{*} \mathrm{xH}_{2} \mathrm{O}$ at the $258 \mathrm{~nm}$, absorbance is 0.2650 and the molar extinction is $0.37^{*} 105\left(\mathrm{~cm}^{-1} \mathrm{M}^{-1}\right)$; for $\mathrm{H}_{3}\left[\mathrm{Si}\left(\mathrm{W}_{12} \mathrm{O}_{40}\right)\right]^{*} \mathrm{xH}_{2} \mathrm{O}$ at the $264 \mathrm{~nm}$, absorbance is 0.3984 and the molar extinction is $0.5^{*} 105\left(\mathrm{~cm}^{-1} \mathrm{M}^{-1}\right)$; for $\mathrm{Na}_{3}\left[\mathrm{P}\left(\mathrm{W}_{12} \mathrm{O}_{40}\right)\right]^{*} \times \mathrm{H}_{2} \mathrm{O}$ at the $251 \mathrm{~nm}$, absorbance is 0.2774 and the molar extinction is $0.34^{*} 105\left(\mathrm{~cm}^{-1} \mathrm{M}^{-1}\right)$.

The spectra of monolacunary compounds (Figure 4) do not show much difference between the two $\alpha$ and $\beta$ forms of the $\left.\mathrm{K}_{7}\left[\mathrm{AsW}_{11} \mathrm{O}_{39}\right]\right]^{*} \mathrm{xH}_{2} \mathrm{O}$ compound: one shows a maximum at $251 \mathrm{~nm}$ and the other at $252 \mathrm{~nm}$.

Trilacunary compounds are both sodium salts: $\left.\mathrm{Na}_{8}\left[\mathrm{HAs} \mathrm{W}_{9} \mathrm{O}_{33}\right]\right]^{*} \mathrm{xH}_{2} \mathrm{O} / \quad \mathrm{Na}_{8}\left[\mathrm{HSbW}_{9} \mathrm{O}_{33}\right]{ }^{*} \mathrm{xH}_{2} \mathrm{O}$ and their spectra are presented in Figure 5. Compounds have the same W addenda and different heteroatoms As/Sb. For $\mathrm{Sb}$ compound, the peak appears at $268 \mathrm{~nm}$ and is more intense than the one for As compound $(255 \mathrm{~nm})$.

The molar extinction for these compounds are: for $\mathrm{Na}_{8}\left[\mathrm{HAsW}_{9} \mathrm{O}_{33}\right]^{*} \mathrm{xH}_{2} \mathrm{O}$ at the $255 \mathrm{~nm}$, absorbance is 0.2010 and the molar extinction is $0.25^{*} 105\left(\mathrm{~cm}^{-1} \mathrm{M}^{-1}\right)$; for $\mathrm{Na}_{8}\left[\mathrm{HSbW}_{9} \mathrm{O}_{33}\right]^{*} \mathrm{xH}_{2} \mathrm{O}$ at the $268 \mathrm{~nm}$, absorbance is 0.1376 and the molar extinction is $0.18^{*} 105\left(\mathrm{~cm}^{-1} \mathrm{M}^{-1}\right)$.

The Clusters spectra are presented in Figure 6. For the $\mathrm{K}$ salt of the arsenotungstate cluster the peak occurs at 261 $\mathrm{nm}$ and for the Na salt at $253 \mathrm{~nm}$. This difference is due to the influence of various internal cations $(\mathrm{Na}, \mathrm{K})$.

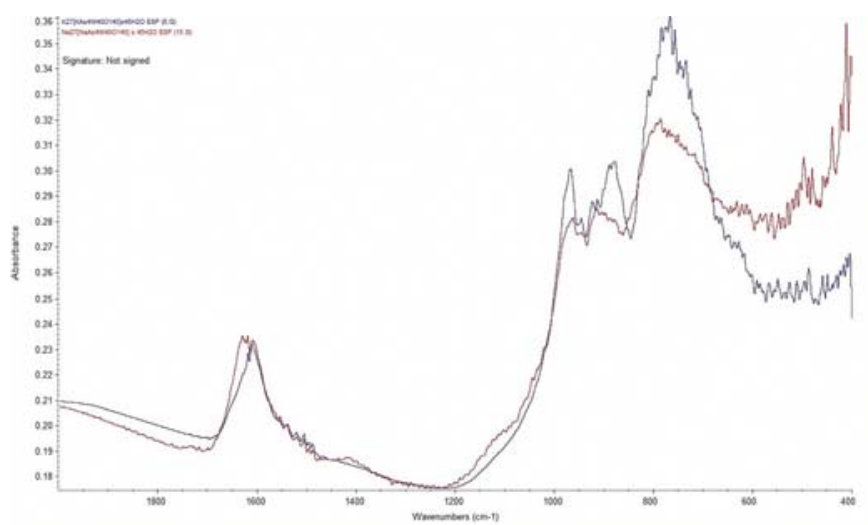

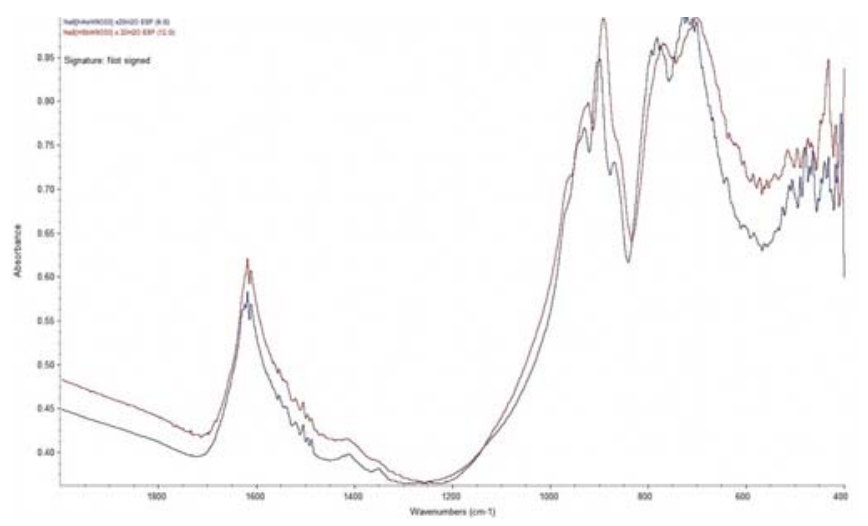

Fig. 9. IR spectra for trilacunary compounds

The molar extinction for these compounds are: for $\mathrm{K}_{27}\left[\mathrm{KAs}_{4} \mathrm{~W}_{40} \mathrm{O}_{140}\right]^{*} \mathrm{xH}_{2} \mathrm{O}$ at the $253 \mathrm{~nm}$, absorbance is 0.3269 and the molar extinction is $1.93^{*} 105\left(\mathrm{~cm}^{-1} \mathrm{M}^{-1}\right)$; for $\mathrm{Na}_{27}\left[\mathrm{NaAs}_{4} \mathrm{~W}_{40} \mathrm{O}_{140}\right]{ }^{*} \times \mathrm{H}_{2} \mathrm{O}$ at the $261 \mathrm{~nm}$, absorbance is 0.1609 and the molar extinction is $1.05^{*} 105\left(\mathrm{~cm}^{-1} \mathrm{M}^{-1}\right)$; for $\mathrm{K}_{23}\left[\mathrm{KAs}_{4} \mathrm{~W}_{40} \mathrm{O}_{140} \mathrm{Co}^{(2+)}\right]^{*} 40 \mathrm{H}_{2} \mathrm{O}$ at the $281 \mathrm{~nm}$, absorbance is 0.2639 and the molar extinction is $1.09^{*} 105$ $\left(\mathrm{cm}^{-1} \mathrm{M}^{-1}\right)$.

\section{b) IR determinations}

By absorption of energy quanta by simple or complex molecule and function of the energy absorbed, several types of molecular energy transitions at higher levels can occur. Information obtained by electronic spectra relates to the electronic structure, the nature of chemical bonds. Values in the spectra correspond to those found in the literature [13-18].

IR spectra study begins with saturated compounds marketed.

In all spectra a peak shows around $1600 \mathrm{~cm}^{-1}$ which is due to water molecules.

The saturated compounds spectra are presented in Figure 7 . In compounds having the tungsten addenda atoms, a peak appears at $981 \mathrm{~cm}^{-1}$ corresponding $\mathrm{W}=\mathrm{Od}$ bond. In Mo compound, the peak corresponding to this connection is at $960 \mathrm{~cm}^{-1}$. W-O-W bridge bonds appear on a wider range, $785-923 \mathrm{~cm}^{-1}$, because there are several types of such bonds (Sidgwick). Si-O bonds appear at $712 \mathrm{~cm}^{-1}$.

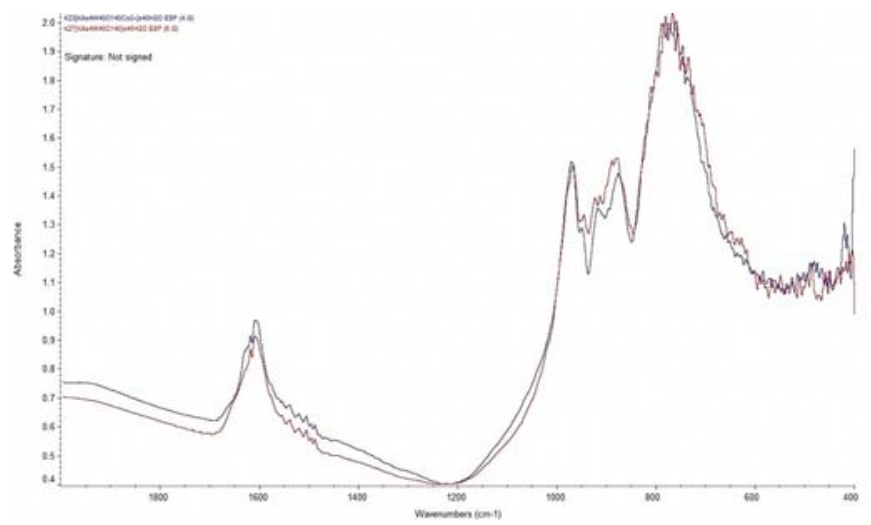

Fig. 10. IR spectra for clusters 
P-O bond appears at $1064 \mathrm{~cm}^{-1}$ in the molybdate complex and at $1080 \mathrm{~cm}^{-1}$ in the tungstate complex, this difference is due to the influence of established connections by octahedron coordination of W/Mo addenda. A slight peak shift appears in the third spectrum due to the sodium cation.

Between the two spectra (Figure 8) of the two isomers $\alpha$ and $\beta$ of the monolacunary compound $\mathrm{K}_{7}\left[\mathrm{AsW}_{11} \mathrm{O}_{39}\right] * \mathrm{xH}_{2} \mathrm{O}$ very small differences appear, for peaks characterizing $\mathrm{W}=\mathrm{Od}$ and $\mathrm{W}-\mathrm{O}-\mathrm{W}$ bonds. A significant difference appears at the As-O bond. While the peak occurs around the same values, the intensity is different.

In spectra of trilacunary compounds $\mathrm{Na}_{8}\left[\mathrm{HAs} \mathrm{W}_{9} \mathrm{O}_{33}\right] * \mathrm{xH}_{2} \mathrm{O} / \mathrm{Na}_{8}\left[\mathrm{HSbW}_{9} \mathrm{O}_{33}\right]{ }^{*} \mathrm{xH}_{2} \mathrm{O}$ (Figure 9), the peaks characterizing the $\mathrm{W}=\mathrm{Od}$ bonds appear at $931 \mathrm{~cm}^{-1}$ for As compound and $923.8 \mathrm{~cm}^{-1}$ for Sb compound. For W-O-W bonds: 782.7 to $900.3 \mathrm{~cm}^{-1}$ for As compound, from 770.8 to $892.6 \mathrm{~cm}^{-1}$ for $\mathrm{Sb}$ compound. For As-O bond the peak is at $729.1 \mathrm{~cm}^{-1}$, while for $\mathrm{Sb}-\mathrm{O}$ it is at $701.7 \mathrm{~cm}^{-1}$. Smaller values of $\mathrm{Sb}$ compound show that the energy ties of this compound are smaller.

For the two clusters (Figure 10) one with $\mathrm{Na}$ and the other with $\mathrm{K}$, characteristic peaks for $\mathrm{W}=\mathrm{Od}$ bond occur at $963.7 \mathrm{~cm}^{-1}$ for $\mathrm{Na}$ compound and $968.2 \mathrm{~cm}^{-1}$ for $\mathrm{K}$ compound. For the $\mathrm{K}$ cluster compound the W-O$\mathrm{W}$ bond peaks are intense. For $\mathrm{Co}^{2+}$ coordinated cluster peaks are well defined; $970.7 \mathrm{~cm}^{-1}$ peak is due to the newly formed W-O-Co bond from $\mathrm{W}=\mathrm{Od}$. These changes show that clusters are stabilized by coordination.

\section{Conclusions}

Similarities appear from the recorded UV and IR spectra, between compounds of the same class, by category association. Very fine displacements of peaks that occur explain the influence of heteroatoms, addenda atoms or coordinated cations.

Small displacements of the bands to higher energies, to higher frequencies, are due to the polioxometalate building flexibility, flexibility that allows cation coordination.

\section{Acknowledgement}

This paper is partly supported by the Sectorial Operational Programme Human Resources Development (SOP HRD), financed from the European Social Fund and by the Romanian Government under the contract number POSDRU 80641.

\section{References}

1. Chen LJ, Zhao JW, Ma PT, et al. An organic-inorganic hybrid nickelsubstituted arsenotungstate consisting of three types of polyoxotungstate units. Inorg Chem Commun. 2010;13:50-53.

2. Kortza U, Müller A, Slageren J, et al. Polyoxometalates: Fascinating structures, unique magnetic properties. Coordination Chemistry Reviews. 2009;253:2315-2327.

3. Chi YN, Cui FY, Lin ZG, et al. Assembly of Cu/Ag - quinoxaline polyoxotungstate hybrids: Influence of Keggin and Wells-Dawson polyanions on the structure. Journal of Solid State Chemistry. 2013;199:230-239.

4. Hill CL, Prosser-McCartha CM. Homogeneous Catalysis by Transition Metal Oxygen Anion Clusters. Coordination Chemistry Reviews. 1995; 143:407-455.

5. Marcu GH. Heteropolioxometalați, Chimia polioxometalaților. Ed.Tehnică. 1997.

6. Pope MT, Muller A. Polyoxometalate Chemistry: An Old Field with New Dimensions in Several Disciplines. Angew Chem. 1991;103:56-70;

7. Sidgwick NV. The Chemical Elements and Their Compounds. Oxford. England, 1951.

8. Contant R. Relations entre les tungstophosphates apparentés à I'anion PW120403-. Synthèse et propriétés d'un nouveau polyoxotungstophosphate lacunaire K1OP2W20070•24H2O. Canadian Journal of Chemistry. 1987;65:568-573.

9. Téazéa A, Hervéa G, Finke RG, Lyon DK. $\alpha$-, ? ?-, and ?-Dodecatungstosilicic Acids: Isomers and Related Lacunary Compounds. Inorg Synth. 1990;27:85-96.

10. DomaillePJ, Hervéa G, Téazéa A. Vanadium(V) Substituted Dodecatungstophosphates. Inorganic Syntheses. 1990;27:96-104.

11. Putaj $P$, Lefebvre F. Polyoxometalates containing late transition and noble metal atoms. Coordination Chemistry Reviews. 2011;255:1642-1685.

12. Yan B, Li YF, Zhao HY, Pan WP, Parkin S. Polyoxometalates functioned as ligands: Synthesis and crystal structure of a new hybrid compound constructed from metatungstate and metal complex units. Inorg Chem Com. 2009;12:1139-1141.

13. Kato M, Kato KN. A Keggin-type polyoxotungstate-coordinated diplatinum(II) complex: Synthesis, characterization, and stability of the cisplatinum(II) moieties in dimethylsulfoxide and water. Inorganic Chemistry Communications. 2011;14:982-985.

14. Car PE, Spingler B, Weyeneth S, Patscheider J, Patzke GR. All-inorganic 1D chain-based architecture of a novel dimanganese-substituted Keggin polyoxotungstate. Polyhedron. 2013;52:151-158.

15. Li MX, Niu HY, Wang W, Wang JP. A Keggin-type arseno-supported transition metal complex: hydrothermal synthesis and characterization. Z.Naturforsch 2008;63b:183-186.

16. Chen WL, Chen BW, Tan HQ, et al. Ionothermal syntheses of three transition-metal-containing polyoxotungstate hybrids exhibiting the photocatalytic and electrocatalytic properties. Journal of Solid State Chemistry. 2010;183:310-321.

17. Miller FA, Wilkins $\mathrm{CH}$. Infrared Spectra and Characteristic Frequencies of Inorganic lons. Anal Chem. 1952;24(8):1253-1294.

18. Zhao X, Li YG, Wang YH, Liu J, Wang EB. Synthesis and characterization of new tungstosilicate aggregates assembled with a mixture of mono- and trivacant Keggin fragments. Inorganica Chimica Acta. 2008;361:359-364. 